ГЕНЕТИЧЕСКИЙ ПОЛИМОРФИЗМ РЕНИН-АНГИОТЕНЗИН-АЛЬДОСТЕРОНОВОЙ СИСТЕМЫ ПРИ САХАРНОМ ДИАБЕТЕ 2 ТИПА И ПРИ СОЧЕТАНИИ С АРТЕРИАЛЬНОЙ ГИПЕРТЕНЗИЕЙ У ЖИТЕЛЕЙ ДАГЕСТАНА

(с) М.3. Саидов ${ }^{1}$, С.Н. Маммаев', Г.М. Магадова', Р.М. Баламирзоева², 3.Ш. Магомедова', З.С. Магомедова' , А.У. Гамзаева'

'Дагестанский государственный медицинский университет, Махачкала

²Республиканский медико-генетический центр Минздрава РД, Махачкала

ОБОСНОВАНИЕ. Сахарный диабет 2 типа (СД2) и артериальная гипертензия (АГ) являются частыми коморбидными состояниями, при которых активация ренин-ангиотензин-альдостероновой системы (РААС) является важным патогенетическим звеном. Функциональное состояние РААС генетически детерминировано. Идентифицированы и картированы генетические полиморфизмы системы РААС, ассоциированные с развитием как СД2, так и АГ. Ассоциации полиморфных вариантов генов РААС с СД2 и АГ среди жителей Дагестана не изучались.

ЦЕЛЬ. Изучение ассоциации наиболее актуальных полиморфных вариантов С521Т и Т704С гена AGT, а также A1166C гена AGTR1 с СД2 и при сочетании СД2 с АГ у жителей Дагестана.

МЕтОДЫ. Обследовано 16 больных с СД2, 59 больных с СД2 в сочетании с АГ и 51 больной с АГ, все жители Дагестана. Контрольная группа включала 47 здоровых лиц той же возрастной группы. SNP-полиморфизмы исследовали методом аллель-специфической Real-Time PCR. Исследованы полиморфизмы C521T и T704C гена AGT, а также полиморфизм A1166C гена AGTR1.

РЕзУЛЬтАТЫ. В группе больных с сочетанием СД2 и АГ генотип СТ полиморфизма С521Т гена AGT встречался реже по сравнению с контролем (23\% против 43\%; $\left.x^{2}=3,868 ; p=0,049\right)$, показатель ОШ - 0,4 (0,2-0,9). Аналогично обстояло дело и с генотипом ТС полиморфизма T704C гена $A G T$ (39\% против 61\%; $\left.\chi^{2}=4,282 ; p=0,039\right)$. ОШ составило 0,4 (0,2-0,8). Напротив, у этих же больных, но носителей гомозиготного генотипа СС полиморфизма T704C гена AGT ОШ превысило единицу и составило 2,5 (1,02-5,9), частота встречаемости 42\% против $23 \%$ ( $\left.X^{2}=3,363, p=0,05\right)$. Частота встречаемости мутантного аллеля С полиморфизма A1166C гена AGTR1 у больных только с АГ составила $31 \%$ против $14 \%$ $\left(X^{2}=5,496, p=0,019\right.$, ОШ 2,5 (1,2-5,0)). Частота встречаемости дикого аллеля А у этих же больных составила 69\% против $84 \%\left(x^{2}=5,496, p=0,019\right.$, ОШ 0,4 (0,2-0,8)). Аналогичная ситуация определялась и с генотипом АА (52\% против 73\%, $\left.x^{2}=3,609, p=0,05\right)$, ОШ $0,4(0,1-0,9)$.

ЗАКЛЮЧЕНИЕ. Ассоциация полиморфизмов С521Т и T704С, а также А1166С генов-кандидатов AGT и AGTR1 с СД2 и АГ является важной составляющей при оценке предрасположенности к развитию этих заболеваний у жителей Дагестана.

КЛЮЧЕВЫЕ СЛОВА: сахарный диабет; артериальная гипертензия; генетический полиморфизм; ренин-ангиотензин-альдостероновая система

\title{
GENETIC POLYMORPHISM OF RENIN-ANGIOTENSIN-ALDOSTERONE SYSTEM IN TYPE 2 DIABETES AND IN COMBINATION WITH ARTERIAL HYPERTENSION AMONG DAGESTAN INHABITANTS
}

(c) Marat Z. Saidov', Suleiman N. Mammaev', Halina M. Magadova', Rita M. Balamirzoeva², Zulfia Sh. Magomedova', Zarema S. Magomedova', Aishat U. Gamzaeva'

'Dagestan State Medical University Makhachkala, Russia

${ }^{2}$ Republican Medical Genetics Center Makhachkala, Russia

BACKGROUND: Type 2 diabetes and arterial hypertension are frequent comorbidities under which activation the reninangiotensin-aldosterone system is important pathogenetic link. The functional state of the RAAS is genetically determined. Genetic polymorphisms of the RAAS system associated with the development of both type 2 diabetes and arterial hypertension have been identified and mapped. Associations of polymorphic variants of the RAAS genes with type 2 diabetes and arterial hypertension among the inhabitants of Dagestan have not been studied.

AIM: Studying the association of the most relevant polymorphic variants of the C521T and T704C AGT gene, as well as the A1166C AGTR1 gene with type 2 diabetes and when combining type 2 diabetes with arterial hypertension among Dagestan inhabitants. 
METHODS: We examined 16 patients with type 2 diabetes, 59 patients with type 2 diabetes combined with arterial hypertension and 51 patients with arterial hypertension, all residents of Dagestan. The control group included 47 healthy persons of the same age group. SNP polymorphisms were investigated by the method of allele-specific Real-Time PCR. The C521T and T704C polymorphisms of the AGT gene and the A1166C polymorphism of the AGTR1 gene were studied.

RESULTS: In the group of patients with a combination type 2 diabetes with arterial hypertension, the genotype CT of the C521T polymorphism of the AGT gene is less common compared to the control ( $23 \%$ vs. $\left.43 \%, X^{2}=3,868, p=0,049\right)$, OR score $-0,4(0,2-0,9)$. The situation is similar with the TC genotype of the T704C polymorphism of the AGT gene (39\% versus $\left.61 \%, X^{2}=4,282, p=0,039\right)$. OR was $0,4(0,2-0,8)$.On the contrary, in the same patients, but the carriers of the homozygous CC genotype of the T704C polymorphism of the AGT gene, OR exceeded one and made 2.5 (1.02-5.9), the frequency of occurrence was $42 \%$ vs. $23 \%, X^{2}=3,363, p=0,05$. The frequency of the mutant allele $C$ of the A $1166 \mathrm{C}$ polymorphism of the AGTR1 gene in patients with arterial hypertension alone was $31 \%$ vs. $14 \%, X^{2}=5.496, p=0,019,0 R-2,5(1,2-5,0)$. The frequency of the wild allele $A$ in these same patients was $69 \%$ versus $84 \%, X^{2}=5,496, p=0,019,0 R-0,4(0,2-0,8)$. A similar situation is determined with the AA genotype ( $52 \%$ versus $\left.73 \%, X^{2}=3,609, p=0,05\right), O R=0,4(0,1-0,9)$.

CONCLUSIONS: The association of the C521T and T704C polymorphisms, as well as the A1166C candidate genes AGT and AGTR1 with type 2 diabetes and arterial hypertension, is an important component in assessing the susceptibility to the development of these diseases in Dagestan residents.

KEYWORDS: diabetes mellitus; essential arterial hypertension; genes polymorphism; renin-angiotensin-aldosterone system.

Сахарный диабет 2 типа (СД2) относится к группе многофакторных заболеваний, при которых стратификация факторов риска вывела генетические полиморфизмы в число наиболее значимых. В настоящее время по результатам полногеномного анализа ассоциаций (Genome-Wide Association Studies - GWAS), а также метода сцепления идентифицировано и картировано около 65 генетических локусов, ассоциированных с развитием СД2 [1].

Ключевые звенья патогенеза СД2 - инсулинорезистентность, гипергликемия, гиперинсулинемия, глюкозотоксичность и осложнения СД2 - ретинопатия, нефропатия, полинейропатия, ангиопатия имеют статистически значимую ассоциацию с генетическими полиморфизмами самой разнообразной локализации и функциональной значимости [2]. На основании многочисленных данных об ассоциации определенных генетических локусов и полиморфизмов с СД2 созданы шкалы генетических рисков СД2 [3].

Важной особенностью течения СД2 является его сочетание с артериальной гипертензией (АГ). При этом причинно-следственные взаимоотношения остаются довольно сложными и противоречивыми. Считается, что АГ встречается у больных СД2 в 60-80\% случаев. В соответствии с результатами исследований [4] в 30-35\% случаев она является эссенциальной АГ, в 40-45\% случаев определяется изолированная систолическая гипертония, а в 25-35\% случаях АГ носит симптоматический характер, вследствие диабетической нефропатии и поражения почечных артерий. По данным Государственного регистра сахарного диабета при СД2 артериальная гипертония регистрируется у $37,6 \%$ пациентов [5].

В патогенезе АГ одним из ключевых звеньев является активность ренин-ангиотензин-альдостероновой системы (РААС). Синтез, продукция и рецепция компонентов PAAС генетически детерминированы. В этой связи к числу наиболее актуальных генов-кандидатов АГ относят полиморфизмы гена ангиотензин-превращающего фермента $(A C E)$, гена ангиотензиногена $(A G T)$ и гена рецептоpa I ангиотензина II (AGTR1). Частота встречаемости этих полиморфизмов в различной степени ассоциирована с АГ, и эти ассоциации носят статистически значимый характер. Особенностью ассоциаций конкретных полиморфных вариантов генов-кандидатов и СД2, и АГ является связь с этнической принадлежностью и регионом проживания больных. Наши исследования подтвердили статистически значимую ассоциацию полиморфизмов генов AGT и AGTR с АГ у жителей Дагестана [6].

В основе сочетания АГ и СД2 лежит инсулинорезистентность (ИР), которая может проявляться повышением уровня АД [7]. Известно, что гиперактивность РААС, увеличение уровня АТ II сопровождаются усилением ИР. Также известно, что повышение сывороточного уровня АТ II и связанные с этим гиперинсулинемия, задержка натрия и воды в организме, увеличение концентрации натрия и кальция внутри клеток поддерживают высокий уровень АД. Высокий уровень АТ II способствует развитию диабетической нефропатии [8].

Эти процессы статистически значимо ассоциированы с определенными генетическими полиморфизмами. Много работ свидетельствуют о взаимоперекрещивающихся генетических факторах АГ и СД2. В частности, показано, что одним из патогенетических механизмов СД2 является ингибиция секреции инсулина, обусловленная активацией $a_{2}$-адренорецептора (ADRa2). Однонуклеотидные полиморфизмы гена $A D R a 2$ ассоциированы с уменьшением продукции инсулина и развитием СД2 [9]. В работе американских авторов показано, что у больных СД2 С-аллель полиморфизма AGT1R 1166 гена рецептора 1 типа ангиотензизина (AGT1R) статистически значимо ассоциирован с диабетической нефропатией у мужчин и женщин, а 235 Т-аллель гена ангиотензиногена (AGT) ассоциирован с коронарной болезнью сердца у женщин. Иными словами, авторами показана значимость генетической составляющей РАAС в патогенезе сосудистых осложнений при СД2 [10]. Определены ассоциации гена ангиотензиногена (AGT) с чувствительностью к инсулину на кавказской популяции. Анализ гаплотипов AGT гена показал, что наибольшее значение имели гаплотипы с точечными мутациями rs2493134 и rs699. Указанные SNP-полиморфизмы статистически значимо были ассоциированы с уровнем сывороточного ангиотензиногена и чувствительностью к инсулину [11]. 
В иранской популяции показано, что диабетическая нефропатия в сочетании с АГ ассоциирована с носительством аллеля C полиморфизма A1166C гена AT1R (рецептора 1 типа ангиотензина II) [12].

Таким образом, эти и другие работы свидетельствуют об очевидной ассоциации полиморфизмов генов-кандидатов РААС с СД2 и АГ. В этой связи представляло интерес изучение ассоциаций полиморфизмов РААС с СД2 и АГ у жителей Дагестана.

\section{ЦЕЛЬ}

Изучение ассоциации наиболее актуальных полиморфных вариантов C521T и T704C гена AGT, а также A1166C гена AGTR1 с СД2 и при сочетании СД2 с АГ у жителей Дагестана.

\section{МЕТОДЫ}

\section{Дизайн исследования}

Работа относится к обсервационным многоцентровым одномоментным выборочным контролируемым нерандомизированным исследованиям. Набор пациентов осуществлялся в эндокринологических медицинских центрах г. Махачкалы (см. ниже). Протокол исследования включал подписание информированного согласия, заполнение карт амбулаторных больных с клиническими диагнозами СД2, АГ и при сочетании СД2 с АГ, куда вносились анамнестические данные, результаты общеклинического обследования, данные лабораторно-инструментальных методов обследования, результаты генетических исследований полиморфизмов генов AGT и AGTR1.

\section{Критерии соответствия}

В исследование включались 3 группы больных, а также контрольная группа.

1 группа больных с установленным диагнозом СД2; 2 группа больных с установленным диагнозом «эссенциальная артериальная гипертензия (гипертоническая болезнь)» при стойком повышении АД в диапазоне 140-159/90-99 мм рт. ст. и выше. 3 группа больных с сочетанием СД2 и АГ. Возраст, пол, ИМТ, способ лечения СД, продолжительность заболевания не относились к критериям включения/невключения в исследование.

Контрольная группа включала 47 лиц с нормальным уровнем АД и с отсутствием симптомов СД2 в возрасте $59(56 ; 61)$ лет (26 мужчин и 33 женщины). Все добровольцы, подписавшие информированное согласие на проведение исследования, в течение последнего месяца перед началом исследования не переносили острых инфекционных заболеваний и не имели хронической патологии воспалительного генеза.

Критерии исключения. Больные с вторичными (симптоматическими) формами АГ исключались из 2 группы обследованных пациентов. Кроме того, исключались больные с хронической сердечной недостаточностью, инфарктом миокарда, инсультом, с патологией других органов и систем, не связанных с СД2 и эссенциальной АГ, которые могли бы повлиять на результаты исследования.
Условия проведения

В работу были включены больные с диагнозами СД2, АГ и СД2 в сочетании с АГ, находившиеся на обследовании и лечении в эндокринологическом отделении Республиканской клинической больницы, на амбулаторном учете в Республиканском эндокринологическом центре РД, а также на базе Республиканского медицинского центра республики Дагестан

\section{Продолжительность исследования}

Исследование продолжалось 2 года (с 2016 по 2018 год).

\section{Описание медицинского вмешательства}

Всем пациентам проводился однократный забор крови из периферической вены в количестве 10 мл для проведения генетических исследований.

\section{Основной исход исследования}

Основным результатом, оценивавшимся в ходе исследования, были различия в частоте встречаемости генотипов и аллелей полиморфизмов С521Т и Т704С гена AGT и A1166C гена AGTR1 при СД2, СД2 в сочетании с АГ и изолированной АГ у жителей Дагестана.

\section{Методы регистрации исходов}

Анализ полиморфных вариантов генов AGT и AGTR1 проводился методом Real-Time PCR. Изучаемые полиморфизмы были представлены единичными заменами нуклеотидов (SNP). Выделение ДНК осуществлялось из цельной крови пациентов и здоровых добровольцев с помощью набора «ДНК-экспресс кровь» («Литех», Россия) согласно инструкции производителя. Амплификацию и плавление изучаемого локуса ДНК проводили на амплификаторе ABI 7900 HT (Applied Biosystems, США) с флуоресцентной детекцией в режиме реального времени. Аллель-специфическую полимеразную цепную реакцию проводили на наборах для генотипирования «SNP-ЭКСПРЕCC-PBКардиогенетика» «Литех». Использовались следующие наборы: на полиморфизмы Thr174Met гена AGT кат. №S01118100, Met235Thr гена AGT кат. №S01119, A1166C гена AGTR1, кат. №S01131-100. С образцами выделенной ДНК проводили одновременно две реакции амплификации - с двумя парами аллель-специфических праймеров на выявление аллелей дикого и мутантного типа (норма и патология соответственно). Компьютерный анализ кривых накопления флуоресцентного сигнала по каждому из образцов ДНК позволил дать качественную оценку отсутствия или наличия мутантного аллеля в гетеро- или гомозиготной форме.

\section{Анализ в подгруппах}

Больные $(n=126)$ были разделены на 3 подгруппы в соответствии с клиническим диагнозом. 1 подгруппа больных с диагнозом СД2 $(\mathrm{n}=16), 2$ подгруппа больных с диагнозом СД2 и АГ $(\mathrm{n}=59)$ и 3 подгруппа больных с изолированной АГ $(\mathrm{n}=51)$. В каждой из выделенных групп больных были проведены генетические исследования. Контрольная группа включала 47 лиц той же возрастной группы.

\section{Этическая экспертиза}

Исследование было одобрено Комитетом по этике при Дагестанском государственном медицинском уни- 
верситете, протокол №9 от 34.10.2016 г. Все пациенты до включения в исследование подписали информированное согласие.

\section{Статистический анализ}

Принципы расчета размера выборки. Размер выборки предварительно не рассчитывался, поскольку исследование носило популяционный характер и предполагало включение в анализ всех случаев СД2, СД2 в сочетании с АГ и изолированной АГ.

Обработку данных проводили с помощью статистического пакета Statistica (версия 6,0), а также Biostat 4.03. База данных создавалась с использованием редактора электронных таблиц Microsoft Excel 2007. Непрерывные переменные в исследуемых выборках представлены в виде медианы (Ме) с 25; 75 процентилями. Для определения статистической значимости различий частот генотипов и аллелей полиморфизмов исследованных генов в основной и контрольной группах использовали таблицы сопряженности и критерий $\mathrm{X}^{2}$. В случаях, когда ожидаемые значения были от 5 до 9, критерий $x^{2}$ рассчитывался с поправкой Йейтса. В случаях, когда хотя бы в одной ячейке ожидаемое значение было меньше 5, использовался точный критерий Фишера. Статистическую значимость различий между двумя сравниваемыми выборками определяли с помощью Т-критерия Манна-Уитни. Критический уровень значимости различий выбирали равным 5\% $(p<0,05)$. Соответствие генотипов по исследованным полиморфным локусам равновесию Харди-Вайнберга оценивали с помощью критерия $X^{2}$.

Степень ассоциации генотипов и аллелей с заболеваниями характеризовалась показателем отношения шансов (ОШ) с 95\% доверительными интервалами (ДИ). Показатель ОШ считался статистически значимым, если ДИ не включал единицу.

\section{РЕЗУЛЬТАТЫ}

\section{Объекты (участники) исследования}

В исследование включены 16 больных СД2 в возрасте $58(52 ; 61)$ лет с длительностью заболевания $6,5(5,2 ; 9,5)$ лет, 59 больных СД2 в сочетании с АГ в возрасте $61(57 ; 63)$ года с длительностью заболевания $12(8,2 ; 18)$ лет и 51 больной с АГ в возрасте $60(54 ; 61)$ лет с длительностью заболевания $10(7,2 ; 15)$ лет. Контрольная группа включала 47 лиц в возрасте 59 (56; 61) лет.

\section{Основные результаты исследования}

Результаты анализа ассоциаций полиморфизма С521Т гена AGT с развитием СД2 и АГ у жителей Дагестана представлены в табл. 1.

Таблица 1. Ассоциация полиморфизма C521T гена AGT с развитием сахарного диабета и артериальной гипертонии у жителей Дагестана

\begin{tabular}{|c|c|c|c|c|}
\hline \multicolumn{5}{|c|}{ СД2 } \\
\hline $\begin{array}{c}\text { Генотипы, аллели } \\
\text { полиморфизма С521Т }\end{array}$ & $\begin{array}{c}\text { СД2 } \\
n=16\end{array}$ & $\begin{array}{c}\text { Контроль } \\
n=47\end{array}$ & $\begin{array}{c}\text { Значение } \mathrm{X}^{2} \text {, } \\
\text { P-value }\end{array}$ & Ош (95\% ди) \\
\hline $\mathrm{CC}$ & $6(43)$ & $26(59)$ & $0,570, p=0,450$ & $0,5(0,1-1,7)$ \\
\hline $\mathrm{CT}$ & $8(57)$ & $17(39)$ & $0,825, p=0,364$ & $2,1(0,6-7,1)$ \\
\hline TT & 0 & $1(2)$ & $p=1,000$ & - \\
\hline C & $20(71)$ & $69(78)$ & $0,225, p=0,614$ & $0,7(0,2-1,8)$ \\
\hline $\mathrm{T}$ & $8(29)$ & $19(22)$ & $0,225, p=0,614$ & $1,4(0,5-3,8)$ \\
\hline \multicolumn{5}{|c|}{ СД2 и АГ } \\
\hline & $\begin{array}{c}\text { СД2 и АГ } \\
n=59\end{array}$ & $\begin{array}{c}\text { Контроль } \\
n=47\end{array}$ & & \\
\hline $\mathrm{CC}$ & $41(72)$ & $24(55)$ & $0,249, p=0,618$ & $1,8(0,7-4,0)$ \\
\hline $\mathrm{CT}$ & $13(23)$ & $19(43)$ & $3,868, p=0,049$ & $0,4(0,2-0,9)$ \\
\hline TT & $3(5)$ & $1(2)$ & $p=1,000$ & $2,4(0,2-23,7)$ \\
\hline C & $95(83)$ & $67(76)$ & $1,198, p=0,274$ & $1,3(0,8-3,1)$ \\
\hline $\mathrm{T}$ & $19(17)$ & $21(24)$ & $1,198, p=0,274$ & $0,6(0,3-1,3)$ \\
\hline \multicolumn{5}{|c|}{$\mathbf{A \Gamma}$} \\
\hline & $\begin{array}{c}A \Gamma \\
n=51\end{array}$ & $\begin{array}{c}\text { Контроль } \\
\mathrm{n}=47\end{array}$ & & \\
\hline $\mathrm{CC}$ & $31(64)$ & $26(59)$ & $0,107, p=0,744$ & $1,3(0,5-2,9)$ \\
\hline $\mathrm{CT}$ & $15(31)$ & $17(39)$ & $0,275, p=0,600$ & $0,7(0,3-1,7)$ \\
\hline TT & $2(5)$ & $1(2)$ & $p=1,000$ & $1,9(0,2-21,3)$ \\
\hline $\mathrm{C}$ & $77(80)$ & $69(78)$ & $0,014, p=0,905$ & $1,1(0,5-2,3)$ \\
\hline $\mathrm{T}$ & $19(20)$ & $19(22)$ & $0,014, p=0,905$ & $0,9(0,4-1,8)$ \\
\hline
\end{tabular}

Примечание: ОШ - отношение шансов с границами 95\% доверительного интервала; частоты генотипов и аллелей представлены в виде абсолютных значений, в скобках относительные доли 
В группе больных СД2 частоты генотипов и аллелей дикого и мутантного типов полиморфизма C521Т гена AGT не отличались от аналогичных показателей в контрольной группе ( $>>0,05$ для всех значений $\left.\mathrm{x}^{2}\right)$, величины ОШ также были статистически незначимыми. Отметим, что по возрастному составу и гендерным различиям группы обследованных больных были сопоставимы с контрольной группой.

Другая картина открывается при анализе ассоциаций в группе больных с сочетанием СД2 и АГ. Видно, что у гетерозигот - носителей генотипа СТ - обнаруживается статистически значимое уменьшение частоты встречаемости указанного генотипа по сравнению с контролем (23\% против 43\%, $\chi^{2}=3,868, p=0,049$ ), и это носительство сопровождается достоверным уменьшением показателя ОШ - 0,4 (0,2-0,9). Этот факт позволяет предположить, что носительство генотипа СТ полиморфизма С521Т гена-кандидата AGT АГ по сравнению с другими генотипами у жителей Дагестана определяет меньшую предрасположенность к СД2.

В 3 обследованной группе больных статистически значимых ассоциаций частот дикого и мутантного аллелей и генотипов полиморфизма C521T гена AGT с пред- расположенностью к АГ нами выявлено не было. Распределение исследованных генотипов не отклонялось от равновесия Харди-Вайнберга.

Результаты оценки ассоциаций полиморфизма Т704С гена AGT с развитием СД2 и АГ у жителей Дагестана представлены в табл. 2.

В группе больных СД2 частоты дикого и мутантного аллелей и генотипов полиморфизма T704C гена $A G T$ не отличаются от аналогичных частот в контрольной группе ( $>0,05$ для всех значений $x^{2}$ ). Но в группе больных с сочетанием СД2 и АГ обнаружено, что частота встречаемости гетерозиготного генотипа ТС полиморфизма Т704С гена AGT у этих больных статистически значимо снижена по сравнению с контролем (39\% против 61\%, $X^{2}=4,282$, $\mathrm{p}=0,039)$. ОШ предрасположенности к СД2 в сочетании с АГ у жителей Дагестана, носителей этого генотипа, составило 0,4 (0,2-0,8). Напротив, у этих же больных, но носителей гомозиготного генотипа СС, ОШ предрасположенности к СД2 в сочетании с АГ превысило единицу и составило $2,5(1,02-5,9)$, а частота встречаемости этого генотипа статистически значимо выше по сравнению с контролем (42\% против 23\%, $\left.X^{2}=3,363, p=0,05\right)$. Иными словами, генотипы ТС и СС полиморфизма T704С гена AGT определяют

Таблица 2. Ассоциация полиморфизма T704С гена AGT с развитием сахарного диабета и артериальной гипертонии у жителей Дагестана

\begin{tabular}{|c|c|c|c|c|}
\hline \multicolumn{5}{|c|}{ СД2 } \\
\hline $\begin{array}{c}\text { Генотипы, } \\
\text { аллели } \\
\text { полиморфизма } \\
\text { Т704С }\end{array}$ & $\begin{array}{c}\text { СД2 } \\
n=16\end{array}$ & $\begin{array}{c}\text { Контроль } \\
n=47\end{array}$ & $\begin{array}{c}\text { Значение } X^{2} \text {, } \\
\text { P-value }\end{array}$ & ОШ (95\% ДИ) \\
\hline TT & $1(7)$ & $7(16)$ & $0,141, p=0,701$ & $0,4(0,04-3,6)$ \\
\hline $\mathrm{TC}$ & $12(86)$ & $27(61)$ & $1,860, p=0,173$ & $3,8(0,7-19,0)$ \\
\hline $\mathrm{CC}$ & $1(7)$ & 41 (47) & $p=0,265$ & $0,2(0,03-2,2)$ \\
\hline $\mathrm{T}$ & $14(50)$ & $47(53)$ & $0,009, p=0,922$ & $1,1(0,5-2,6)$ \\
\hline $\mathrm{C}$ & $14(50)$ & & $0,009, p=0,922$ & $0,9(0,3-2,0)$ \\
\hline \multicolumn{5}{|c|}{ СД2 и АГ } \\
\hline & $\begin{array}{c}\text { СД2 и АГ } \\
n=59\end{array}$ & $\begin{array}{c}\text { Контроль } \\
n=47\end{array}$ & & \\
\hline TT & $11(19)$ & $7(16)$ & $0,032, p=0,858$ & $1,3(0,04-3,5)$ \\
\hline $\mathrm{TC}$ & $22(39)$ & $27(61)$ & $4,282, p=0,039$ & $0,4(0,2-0,8)$ \\
\hline $\mathrm{CC}$ & $24(42)$ & $10(23)$ & $3,363, p=0,05$ & $2,5(1,02-5,9)$ \\
\hline $\mathrm{T}$ & $44(38)$ & $41(47)$ & $0,995, p=0,319$ & $0,7(0,4-1,3)$ \\
\hline C & $70(62)$ & $47(53)$ & $0,995, p=0,319$ & $1,4(0,8-2,4)$ \\
\hline \multicolumn{5}{|c|}{ AГ } \\
\hline & $\begin{array}{c}A \Gamma \\
n=51\end{array}$ & $\begin{array}{c}\text { Контроль } \\
n=47\end{array}$ & & \\
\hline TT & $4(8)$ & $7(16)$ & $0,635, p=0,425$ & $0,5(0,1-1,7)$ \\
\hline $\mathrm{TC}$ & $32(67)$ & $27(61)$ & $0,097, p=0,755$ & $1,2(0,5-2,9)$ \\
\hline $\mathrm{CC}$ & $12(25)$ & $10(23)$ & $0,000, p=0,992$ & $1,1(0,4-2,8)$ \\
\hline $\mathrm{T}$ & $40(42)$ & $41(47)$ & $0,274, p=0,601$ & $0,8(0,4-1,4)$ \\
\hline C & $56(58)$ & $47(53)$ & $0,274, p=0,601$ & $1,2(0,7-2,1)$ \\
\hline
\end{tabular}

Примечание: ОШ - отношение шансов с границами 95\% доверительного интервала; частоты генотипов и аллелей представлены в виде абсолютных значений, в скобках относительные доли 
различные ассоциации с СД2 в сочетании с АГ, в первом случае отмечается тенденция к снижению предрасположенности, а во втором - тенденция к повышению предрасположенности к СД2 в сочетании с АГ.

В группе больных АГ статистически значимых изменений частот встречаемости аллелей дикого и мутантного типов, а также генотипов изученного полиморфизма по сравнению с контрольной группой не определялось.

Результаты изучения ассоциаций полиморфизма A1166C гена AGTR1 с развитием СД2 и АГ у жителей Дагестана представлены в табл. 3.

В группах больных СД2 и СД2 в сочетании с АГ статистически значимых изменений частот встречаемости аллелей дикого и мутантного типов, а также генотипов полиморфизма A1166C гена AGTR1 по сравнению с контрольной группой не определялось. Однако в группе больных с АГ видна совершенно иная картина. Частота встречаемости мутантного аллеля С у больных АГ статистически значимо превышала аналогичный показатель в контрольной группе (31\% против 14\%; $X^{2}=5,496$; $\mathrm{p}=0,019)$. ОШ предрасположенности к АГ у носителей этого аллеля составило 2,5 (1,2-5,0). Напротив, частота встречаемости дикого аллеля А у больных АГ была стати- стически значимо меньше по сравнению с контрольной группой (69\% против 84\%; $\left.\chi^{2}=5,496 ; p=0,019\right)$. ОШ в этой ситуации составило 0,4 (0,2-0,8). Аналогично обстоит дело и с генотипом АA (52\% против 73\%; $X^{2}=3,609$; $\mathrm{p}=0,05)$, ОШ=0,4 $(0,1-0,9)$. Иными словами, представленные результаты свидетельствуют об ассоциации полиморфных вариантов А1166C гена AGTR1 с АГ, но не с СД2 и СД2 в сочетании с АГ.

Нежелательные явления

В процессе исследования нежелательных явлений не зарегистрировано.

\section{ОБСУЖДЕНИЕ}

Резюме основного результата исследования

В группе больных с сочетанием СД2 и АГ показана независимая ассоциация гетерозиготного генотипа СТ полиморфизма C521T гена AGT системы PAAC в сторону уменьшения частоты встречаемости этого генотипа по сравнению с контрольной группой.

В этой же группе больных частота встречаемости гетерозиготного генотипа ТС полиморфизма T704С гена

Таблица 3. Ассоциация полиморфизма A1166C гена AGTR1 с развитием сахарного диабета и артериальной гипертонии у жителей Дагестана

\begin{tabular}{|c|c|c|c|c|}
\hline \multicolumn{5}{|c|}{ СД2 } \\
\hline $\begin{array}{c}\text { Генотипы, } \\
\text { аллели } \\
\text { полиморфизма } \\
\text { А1166C }\end{array}$ & $\begin{array}{c}\text { СД2 } \\
n=16\end{array}$ & $\begin{array}{c}\text { Контроль } \\
n=47\end{array}$ & $\begin{array}{c}\text { Значение } \mathrm{X}^{2} \text {, } \\
\text { P-value }\end{array}$ & Ош (95\%ди) \\
\hline$A A$ & $9(64)$ & $29(66)$ & $0,045, p=0,833$ & $0,9(0,3-3,2)$ \\
\hline$A C$ & $5(36)$ & $12(27)$ & $0,071, p=0,789$ & $1,4(0,4-5,3)$ \\
\hline $\mathrm{CC}$ & 0 & $3(7)$ & $p=1,000$ & - \\
\hline$A$ & $23(82)$ & $70(80)$ & $0,001, p=0,978$ & $1,1(0,4-3,5)$ \\
\hline C & $5(18)$ & $18(20)$ & $0,001, p=0,978$ & $0,8(0,3-2,5)$ \\
\hline \multicolumn{5}{|c|}{ СД2 и АГ } \\
\hline & $\begin{array}{c}\text { СД2 и АГ } \\
n=59\end{array}$ & $\begin{array}{c}\text { Контроль } \\
n=47\end{array}$ & & \\
\hline$A A$ & $36(63)$ & $29(66)$ & $0,006, p=0,939$ & $0,8(0,3-2,0)$ \\
\hline$A C$ & $15(26)$ & $12(27)$ & $0,014, p=0,905$ & $0,9(0,4-2,3)$ \\
\hline $\mathrm{CC}$ & $6(11)$ & $3(7)$ & $0,088, p=0,767$ & $1,6(0,4-6,8)$ \\
\hline A & $87(76)$ & $70(80)$ & $0,142, p=0,707$ & $0,8(0,4-1,6)$ \\
\hline C & $27(24)$ & $18(20)$ & $0,142, p=0,707$ & $1,2(0,6-2,3)$ \\
\hline \multicolumn{5}{|c|}{ AГ } \\
\hline & $\underset{n=51}{A \Gamma}$ & $\begin{array}{c}\text { Контроль } \\
n=47\end{array}$ & & \\
\hline AA & $25(52)$ & $33(73)$ & $3,609, p=0,05$ & $0,4(0,1-0,9)$ \\
\hline$A C$ & $16(33)$ & $10(22)$ & $0,925, p=0,336$ & $1,7(0,7-4,4)$ \\
\hline $\mathrm{CC}$ & $7(15)$ & $2(5)$ & $p=0,160$ & $3,6(0,7-18,7)$ \\
\hline$A$ & $66(69)$ & $76(84)$ & $5,496, p=0,019$ & $0,4(0,2-0,8)$ \\
\hline C & $30(31)$ & $14(16)$ & $5,496, p=0,019$ & $2,5(1,2-5,0)$ \\
\hline
\end{tabular}

Примечание: ОШ - отношение шансов с границами 95\% доверительного интервала; частоты генотипов и аллелей представлены в виде абсолютных значений, в скобках относительные доли. 
AGT системы РАAС статистически значимо снижена по сравнению с контролем. Напротив, у этих же больных, но носителей гомозиготного генотипа СС, ОШ предрасположенности к СД2 в сочетании с АГ превысило единицу и составило 2,5 (1,02-5,9), а частота встречаемости этого генотипа статистически значимо выше по сравнению с контролем.

У больных АГ частота встречаемости мутантного аллеля С полиморфизма A1166C гена AGTR1 системы PAAC статистически значимо превышала аналогичный показатель в контрольной группе. ОШ предрасположенности к АГ у носителей этого аллеля составило 2,5 (1,2-5,0). Частота встречаемости дикого аллеля А и генотипа AА у больных АГ была статистически значимо меньше по сравнению с контрольной группой. ОШ в первом случае составило $0,4(0,2-0,8)$, а во втором - 0,4 $(0,1-0,9)$.

\section{Обсуждение основного результата исследования}

Генетический базис СД2 является достаточно обширным и включает в себя около 65 идентифицированных и картированных генетических локусов [1]. Система РАAС занимает пограничное положение в патогенетических схемах сочетания СД2 и АГ. Единственной молекулярногенетической основой сочетания СД2 и АГ является генетический полиморфизм РААС, поскольку изменения функциональной активности этой системы являются патогенетическим звеном и инсулинорезистентности, и повышения АД. Очевидно, что изменения функционального состояния системы РААС являются патогенетически значимыми как при СД2, так и при АГ. Один из факторов ИР, являющейся основой сочетания АГ и СД2 - активация РАAС, сопровождающаяся увеличением сывороточного уровня АТ II и, как следствие, гиперинсулинемией и задержкой натрия и воды в организме [8]. Многие работы подтверждают ассоциацию полиморфных вариантов генов РААС с СД2 и АГ, а также прогностическую и персонифицированную значимость генетического тестирования конкретного индивидуума [2, 3].

Результаты нашего исследования являются предварительными, и они свидетельствуют о наличии ассоциаций полиморфизмов генов PAAC (AGT u AGTR1) у больных с сочетанием СД2 и АГ и у больных с АГ, жителей Дагестана. Эти ассоциации носили неоднозначный характер. Так, у больных с сочетанием СД2 и АГ, носителей генотипа СТ полиморфизма C521T гена $A G T$, а также у носителей генотипа ТC полиморфизма T704С того же гена значения ОШ были ниже единицы по сравнению с контролем: 0,4 (0,2-0,9) и 0,4 (0,2-0,8) соответственно. Иными словами, при сочетании СД2 и АГ у жителей Дагестана частота встречаемости указанных полиморфизмов меньше по сравнению с контролем. В то же время у этих же больных, но носителей генотипа СС полиморфизма Т704С гена $A G T$, ОШ составило 2,5 (1,02-5,9), что свидетельствует о повышении частоты встречаемости этого генотипа по сравнению с контролем. В группе больных только СД2 статистически значимых ассоциаций зарегистрировано не было. В группе больных с АГ, жителей Дагестана, также зарегистрирована неоднозначная ситуация: повышение частоты встречаемости мутантного аллеля С полиморфизма A1166C гена AGTR1 и значения ОШ и уменьшение частоты встречаемости дикого аллеля $A$ и генотипа $A A$ этого полиморфизма. ОШ в последнем случае составило
0,4 (0,1-0,9). Очевидно, что интерпретация полученных результатов должна включать в себя, во-первых, констатацию наличия конкретных ассоциаций и, во-вторых, учитывать причинно-следственную взаимосвязь полиморфизмов генов РААС с СД2 и АГ, о которой было сказано выше.

Однако ряд работ, выполненных в ведущих научных центрах, свидетельствует об ограниченности прогностической ценности генетического тестирования и соответствующих расчетов генетических шкал риска. Так, поперечные исследования SNP-полиморфизмов, включавших до 9000 индивидуумов с СД2 и без него, показали, что С-статистика (площадь, заключенная под характеристической ROC-кривой) составила от 0,54 до 0,63, что свидетельствует об ограниченной роли генетических факторов в риске развития СД2 [13]. Эти результаты позволили авторам сделать заключение о незначительной роли генетического тестирования в клинической практике. Тем не менее, генетическая детерминированность системы PAAC, участие этой системы в патогенезе АГ и СД2, в том числе и при сочетании этих заболеваний, определяют обоснованность и необходимость включения генетических анализов в комплексное обследование больных СД2 и АГ.

\section{Ограничения исследования}

Дизайн настоящего исследования, констатация наличия генетических полиморфизмов системы РААС не позволяют делать однозначные выводы о причинно-следственных взаимосвязях между изученными полиморфизмами генов РААС и СД2, а также СД2 в сочетании с АГ у жителей Дагестана. В связи с тем, что исследование предполагало анализ всех случаев СД2, СД2 в сочетании с АГ и изолированной АГ выборку следует рассматривать как нерепрезентативную. Относительно небольшой объем выборки и низкая распространенность некоторых генотипов и аллелей в обследованных группах требуют осторожности при интерпретации полученных данных.

\section{ЗАКЛЮЧЕНИЕ}

Полиморфные варианты генов РААС в различной степени ассоциированы с развитием СД2, СД2 в сочетании с АГ и АГ у жителей Дагестана. При СД2 статистически значимых ассоциаций полиморфизмов С521Т и Т704С гена AGT и полиморфизма A1166C гена AGTR1 выявлено не было. Однако при сочетании СД2 и АГ гетерозиготный генотип СТ полиморфизма С521T гена AGT, а также генотип ТC полиморфизма T704C гена AGT ассоциирован с меньшей вероятностью развития СД2 в сочетании с АГ. В то же время у носителей гомозиготного генотипа CC полиморфизма T704C гена AGT вероятность развития СД2 в сочетании с АГ повышается. У больных с изолированной АГ мутантный аллель С полиморфизма А1166C гена AGTR1 ассоциирован с повышенной вероятностью развития АГ, а носительство дикого аллеля А и генотипа АА того же полиморфизма ассоциировано с противоположной тенденцией.

На данный момент времени интерпретация результатов генетического тестирования не выходит за рамки констатации статистически значимых ассоциаций полиморфизмов с СД2 и АГ, расчетов величины риска в отношении развития заболевания либо, наоборот, в отноше- 
нии некоторой "устойчивости» к нему, а также оценки вклада этих ассоциаций в прогностические шкалы риска развития СД2 и АГ. Тем не менее, не преувеличивая значения генетических исследований в клинической практике, оценка SNP-полиморфизмов генов-кандидатов СД2 и АГ перспективна в отношении персонификации предикторов СД2 и АГ.

\section{ДОПОЛНИТЕЛЬНАЯ ИНФОРМАЦИЯ}

Источник финансирования. Работа выполнена за счет средств государственного задания Дагестанского государственного медицинского университета.
Конфликт интересов. Авторы декларируют отсутствие явных и потенциальных конфликтов интересов, связанных с публикацией настоящей статьи.

Участие авторов. Саидов М.3. - концепция и дизайн исследования, статистическая обработка результатов, анализ данных, интерпретация результатов, написание текста; Маммаев С.Н. - концепция и дизайн исследования, анализ данных; Магадова Г.М. - сбор клинического материала, анализ данных; Баламирзоева Р.М. - выполнение молекулярно-генетических исследований; Магомедова 3.Ш. - сбор клинического материала, анализ данных; Магомедова 3.С. - сбор клинического материала; Гамзаева А.У. - сбор клинического материала. Все авторы внесли существенный вклад в проведение исследования и подготовку статьи, прочли и одобрили финальный вариант перед публикацией.

\section{СПИСОК ЛИТЕРАТУРЫ | REFERENCES}

1. Hivert MF, Vassy JL, Meigs JB. Susceptibility to type 2 diabetes mellitus — from genes to prevention. Nat Rev Endocrinol. 2014;10(4): 198-205. doi:10.1038/nrendo.2014.11

2. Vassy JL, Meigs JB. Is Genetic testing useful to predict type 2 diabetes? BMJ .2011;343:d7163

3. Noble D, Mathur R, Dent T, et al. Risk models and scores for type 2 diabetes: systematic review. Best Pract Res Clin Endocrinol Metab. 2012; 26(2): 189-201. doi: 10.1016/j.beem.2011.09.002

4. Волков В.С., Руденко Е.В., Роккина С.А., Поселюгина О.Б. К патогенезу артериальной гипертонии при сахарном диабете 2 типа // Сахарный дuaбem. - 2011.- №2.- C.53-55. [Volkov VS, Rudenko EV, Rokkina SA, Poselyugina OB. On pathogenesis of arterial hypertension in type 2 diabetes mellitus. Diabetes mellitus. 2011;2:53-55. (In Russ.)]

5. Дедов И.И., Шестакова М.В., Викулова О.К. Государственный регистр сахарного диабета в Российской Федерации: статус 2014 г. и перспективы развития // Сахарный диабет. 2015. -T.18. - №3. - C. 5-22. [Dedov II, Shestakova MV, Vikulova OK. National register of diabetes mellitus in Russian Federation. Diabetes mellitus. 2015;18(3):5-22. (In Russ.)] doi: 10.14341/DM201535-22

6. Саидов М.3., Маммаев С.Н., Абдуллаев А.А., и др. Полиморфизмы генов ренин-ангиотензин-альдостероновой системы и связь с вазопрессорами при эссенциальной артериальной гипертензии в дагестанской популяции // Российский кардиологический журнал. - 2017.- №4. - C. 61-69 [Saidov MZ, Mammaev SN, Abdullaev SN, et al. Renin-angiotensinaldosterone system genes polymorphism and relation with vasopressors in essential hypertension among dagestan inhabitants. Russian Journal of Cardiology. 2017;(4): 61-69. (In Russ.)] https://doi.org/10.15829/1560-4071-2017-4-61-69

7. Шарипов Р.А. Артериальная гипертензия и сахарный диабет // Российский кардиологический журнал. - 2008.- №3. - C.71-75 [Sharipov R.A. Arterial hypertension and diabetes mellitus. Russian Journal of Cardiology. 2008;(3):71-75.(In Russ.)] https://doi.org/10.15829/1560-4071-2008-3-71-75

8. Ribeiro-Oliveira Jr.A, Nogueira Al, Pereira RM, et al. The reninangiotensin system and diabetes: An update. Vascular Health and Risk Management 2008:4(4): 787-803

9. Liggett SB. Alpha2A-adrenergic receptors in the genetics, pathogenesis, and treatment of type 2 diabetes. Sci Transl Med. 2009;1 (12):12ps15. doi: 10.1126/scitransImed.3000606

10. Lin J, Hu FB, Qi L and Curhan GC. Genetic polymorphisms of angiotensin-2 type 1 receptor and angiotensinogen and risk of renal dysfunction and coronary heart disease in type 2 diabetes mellitus. BMC Nephrology. 2009; 10:9. doi:10.1186/1471-2369-10-9

11. Underwood PC, Sun B, Williams JS, et al. The Association of the Angiotensinogen Gene with Insulin Sensitivity in Humans: A Tagging SNPs and Haplotype. Approach Metabolism. 201; 60(8): 1150-1157. doi:10.1016/j.metabol.2010.12.009

12. Moradi M, Rahimi Z, Amiri S, et al. AT1R A1166C variants in patients with type 2 diabetes mellitus and diabetic nephropathy. J.Nephropathol.2015;4(3):69-76 doi: 10.12860/jnp.2015.14

13. Lyssenko V, Laakso M. Genetic Screening for the Risk of Type 2 Diabetes Worthless or valuable? Diabetes Care. 2013; 36(Suppl 2): S120-S126. doi: 10.2337/dcS13-2009

\section{ИНФОРМАЦИЯ ОБ АВТОРАХ [AUTHORS INFO]}

*Саидов Марат Зиявдинович, д.м.н., профессор [Marat Z. Saidov, MD, PhD, Professor]; адрес: Россия, Республика Дагестан, 367000, Махачкала, пл. Ленина, 1 [address: Lenin sq.1 Mahachkala, 367000, Russian Federation]; ORCID: https://orcid.org/0000-0001-6246-4482; eLibrary SPIN:5390-4810; e-mail: marat.saidov.55@mail.ru, тел. 8-988-300-90-45

Маммаев Сулейман Нураттинович, д.м.Н., профессор [Suleiman N. Mammaev, MD, PhD, Professor]; ORCID: https://orcid.org/0000-0001-8898-8831; e-library SPIN:6545-7312; e-mail: hepar-sul-dag@mail.ru Магадова Галина Магадовна, врач-эндокринолог [Halina M. Magadova, MD];

ORCID: https://orcid.org/0000-0002-9925-4793; eLibrary SPIN:2118-3782; e-mail: hepar-sul-dag@mail.ru

Баламирзоева Рита Маратовна, к.б.н. [Rita M. Balamirzoeva, MD, PhD in Biology]; Ахмет-хана Султана, 12-а]; ORCID: https://orcid.org/0000-0003-0017-9648; eLibrary SPIN:4101-1987; e-mail:rita.balamirzoeva@mail.ru

Магомедова Зульфия Шамильевна, к.м.H. [Zulfia Sh. Magomedova MD, PhD];

ORCID: https://orcid.org/0000-0002-9860-9820; eLibrary SPIN: 1052-9767, e-mail: zulamag@mail.ru

Магомедова Зарема Саидовна, к.M.н. [Zarema S. Magomedova, MD, PhD];

ORCID: https://orcid.org/0000-0003-4547-1642; eLibrary SPIN:1569-5109; e-mail: amiiiina@mail.ru

Гамзаева Айшат Увайсовна, к.м.н. [Aishat U. Gamzaeva, MD, PhD];

ORCID: https://orcid.org/0000-0003-0958-2644; eLibrary SPIN:7888-7356; e-mail: gamzayeva57@bk.ru 


\section{ЦИТИРОВАТЬ:}

Саидов М.З., Маммаев С.Н., Магадова Г.М., Баламирзоева Р.М., Магомедова 3.Ш., Магомедова 3.С., Гамзаева А.У. Генетический полиморфизм ренин-ангиотензин-альдостероновой системы при сахарном диабете 2 типа и при сочетании с артериальной гипертензией у жителей Дагестана // Сахарный диабет. — 2019. — Т. 22. — №6. — С. 568-576. doi: https://doi.org/10.14341/DM10207

\section{TO CITE THIS ARTICLE:}

Saidov MZ, Mammaev SN, Magadova HM, Balamirzoeva RM, Magomedova ZS, Magomedova ZS, Gamzaeva AU. Genetic polymorphism of renin-angiotensin-aldosterone system in type 2 diabetes and in combination with arterial hypertension among Dagestan inhabitants. Diabetes Mellitus. 2019;22(6):568-576. doi: https://doi.org/10.14341/DM10207 